\title{
3rd TRIMESTER OF PREGNANCY; FREQUENCY OF ANEMIA
}

1. Consultant Gynaecologist Fatima Jinnah Women Hospital, Multan.

2. MBBS, MD

Chief Research Officer, PMRC Research Centre, Nishtar Medical College, Multan 3. M. Sc, M. Phil

Research Officer PMRC Research Centre, Nishtar Medical College, Multan

Correspondence Address: Dr. Nasira Naseem H. No. $1777 / \mathrm{B}$,

Mohallah Chah Bajian Wala,

Old Chungi No. 9

Hazoori Bagh Road Multan

nasira2001@gmail.com

Article received on:

04/08/2014

Accepted for publication:

27/09/2014

Received after proof reading:

15/12/2014

\section{Dr. Nasira Naseem ${ }^{1}$, Dr. Ijaz-Ul-Haque Taseer $^{2}$, Mr. Sohail Safdar ${ }^{3}$}

ABSTRACT... Objective: To see the frequency of anemia in pregnant ladies and its possible outcomes. Study design: Descriptive cross sectional study. Setting: Fatima Jinnah Women Hospital, Multan. Duration of study: Six months. Material and method: This prospective cross sectional study was conducted at Gynae and Obst. OPD at Fatima Jinnah Women Hospital, Multan. Non probability convenient sampling technique was used. All the pregnant women between 20-35 years irrespective of gestational age or any concurrent illness having parity upto 5 were registered for the study after getting written consent for participation. The pregnant ladies were evaluated by asking history of blood loss, parity, multiple pregnancy, worm infestation, use of NSAIDS and blood transfusion. They were especially asked about dietary habits which were rated as good, average and poor. Their socio economic status was assessed and was placed into high, middle and low income groups. Blood samples were drawn for blood counts and hemoglobin estimation in all the women presenting at hospital. Reflotron photometer, Roche Diagnostic was used for the blood testing. A cut off value of $<11 \mathrm{~g} / \mathrm{dl}$ irrespective of duration of pregnancy was used for anemia. Peripheral blood film was examined for RBC morphology. Mean corpuscular volume (MCV) was used to categorize into micorcytic $(<76 \mathrm{fl})$, macrocytic (>98fl) and normocytic (78-98fl). Fetal well being was evaluated by serial abdominal ultrasounds. Results: Three hundred pregnant women attending Gyne and Obst. OPD, Fatima Jinnah Women Hospital, Multan, were registered according to the study protocol. The duration of the study was 6 months. Maternal age was between $25-35$ years. $86 \%$ women were multiparous, $79 \%$ women presented during 3rd trimester, $15 \%$ during the 2 nd trimester and $6 \%$ during 1 st trimester. Thirty eight percent women had hemoglobin 8-9.9 g/dl, $48 \%$ had from 7-7.9 g/dl and 10\%were falling between 5-7 g/dl. Eighty eight percent had microcytic hypochromic anemia, $12 \%$ with dimorphic picture and $4 \%$ were having low MCV and $\mathrm{MCH}$ but normal $\mathrm{MCHC}$ and these were referred for hemoglobin electrophoresis. Fifty eight percent had monthly income 2-4 thousands rupees and only 10\% were earning 4-10 thousands per month. Seventy eight percent had poor diet and $22 \%$ had an average and no women were fit into the criteria for good diet. History of breast feeding was positive in $92 \%$ of the women. History of use of iron supplement was also asked, $28 \%$ had used various preparations of iron and folate for a variable period from 1-4 months, $72 \%$ never used hematinic supplements. History of previous blood transfusion during pregnancy and labour was present in $16 \%$ of the women. Three percent had fetal growth retardation. Conclusions: Prevalence of anemia during 3rd trimester of pregnancy in is high our society. It can have significant effects on maternal and fetal out come. It is a preventable cause which can be treated easily. Poverty and lack of education are the most important causes of anemia during pregnancy.

Key words: Anemia, pregnancy, pregnancy out come.

Article Citation: Naseem N, Taseer IH, Safdar S. $3^{\text {rd }}$ trimester of pregnancy; frequency of anemia. Professional Med J 2014; 21(6):1113-1116.

\section{INTRODUCTION}

Anemia affects an estimated 400 million women worldwide and most women are unaware of symptoms and tend to attribute such mild symptoms to the stresses of modern life. It literary means "without blood", and refers to a condition where there is deficiency of blood. There are marked physiological changes in the blood composition during healthy pregnancy to combat the risk of haemorrhage at delivery, plasma volume and red cells mass increases by $50 \%$ and $18-25 \%$ respectively ${ }^{1}$. This results in dilutational decrease in haemogloin concentration called physiological anemia of pregnancy and it occurs maximum at 
32 weeks of gestation ${ }^{2}$. WHO has recommended a cut off value of $11 \mathrm{~g} / \mathrm{dl}$ to define anemia at any time during pregnancy ${ }^{3}$. Pathological anemia of pregnancy is mainly due to iron deficiency ${ }^{4}$. Folate deficiency has a minor contribution towards anemia ${ }^{5}$. Folate deficiency may be masked by co-existing iron deficiency. Deleterious effects of anemia occur in mother, as well as, in baby which is multi factorial in community like ours. Multiparity, poor socio economic and lack of education are principal reasons for high prevalence of anemia in our population. Present study was conducted at Fatima Jinnah Women Hospital Multan to see the frequency of iron deficiency anemia in pregnant ladies, and to see its possible outcomes.

\section{METHODOLOGY}

This prospective cross sectional study was conducted at Gynae and Obst. OPD at Fatima Jinnah Women Hospital, Multan. Non probability convenient sampling technique was used. All the pregnant women between 20-35 years of age irrespective of gestational age or any concurrent illness having parity upto 5 were registered for the study after getting written consent for participation. The pregnant ladies were evaluated by asking history of blood loss, fetal loss, history of multiple pregnancies, history of worm infestation, history of use of NSAIDS, multi parities, history of blood transfusion They were specially asked about dietary habits which were rated as good, average and poor. Their socio economic status was assessed and was placed into high, middle and low income for RBC morphology groups. Peripheral blood film was examined. Blood samples were drawn for blood counts and hemoglobin estimation in all the women presenting at hospital. Reflotron photometer, Roche diagnostic was used for the blood testing. A cut off value of less than $11 \mathrm{~g} /$ $\mathrm{dl}$ irrespective of duration of pregnancy was used to define anemia ${ }^{7}$. Mean corpuscular volume (MCV) was used to categorize into microcytic and macrocytic. If MCV was less than $76 \mathrm{fl}$ the RBC were labeled as microcytic and if MCV was more than $98 \mathrm{fl}$ RBC were labelled as macrocytic. With MCV between $76 \mathrm{fl}$ to $98 \mathrm{fl}$, the RBCs were labeled as normocytic appearance ${ }^{6,7}$. A fetal well being was evaluated by serial abdominal ultrasounds.

\section{RESULTS}

Three hundred pregnant women attending Gyne and Obst. OPD, Fatima Jinnah Women Hospital, Multan, were registered according to the study protocol. The duration of the study was 6 months. Maternal age was between 25-35 years. Eighty six $(86 \%)$ women were multiparous, $79 \%$ women presented during 3rd trimester, 15\% during the $2^{\text {nd }}$ trimester and 6\% during 1st trimester. Hemoglobin was up to $10 \mathrm{~g} / \mathrm{dl}$ in $96 \%$ of women, $38 \%$ women had haemoglobin $8-9.9 \mathrm{~g} / \mathrm{dl}, 48 \%$ had haemoglobin from 7-7.9 g/dl and $10 \%$ had haemoglobin from 5-7 g/dl. Eighty eight percent (88\%) had hypochromic microcytic anemia, $12 \%$ had dimorphic picture and $4 \%$ had low MCV and $\mathrm{MCH}$ but normal $\mathrm{MCHC}$ and these were referred for hemoglobin electrophoresis. The socio economic status was also assessed. Fifty eight percent (58\%) had monthly income 2-4 thousands and only $10 \%$ had monthly income $4-10$ thousands. Their dietary habits were also assessed .Seventy eight per cent(78\%) had poor diet and (22\%) had an average diet and no women was fit into the criteria for good diet. History of breast feeding was positive in(92\%) of the women. History of use of iron supplement was also asked, $28 \%$ had used various preparation of iron and folate for a variable period from 1-4 months, $72 \%$ never used hematinic supplements. History of previous blood transfusion during pregnancy and labour was present in $16 \%$ of the women. Three percent (3\%) of the women had fetal growth retardation.

\section{DISCUSSION}

Anemia in pregnancy is an important preventable cause of maternal and fetal morbidity and mortality, as in non industrialized countries, anemia is associated with upto $13 \%$ of maternal deaths. It is an important public health issue worldwide. WHO estimates that more than half of the women in the world have hemoglobin level indicative of anemia that is haemoglobin less than $11 \mathrm{~g} / \mathrm{dl}$. The prevalence of anemia in the developing countries may be as high as $56-61 \%$, in Pakistan it ranges $8-33 \%$. Neonatal mortality is 20 times more likely to occur in low birth weight 
babies ${ }^{9}$. The anemia of pregnancy increases the risk of low birth weight and intra uterine growth retardation. High prevalence of anemia has been observed in this study, the results are comparable with another study from Nigeria ${ }^{10}$.

Anemia is also an established risk factor for neonatal morbidity ${ }^{11,12}$. In present study $38 \%$ had mild anemia while $48 \%$ of the patients had moderate anemia and $10 \%$ had severe anemia. These results are comparable with the study conducted by Awan et al from Multan where the moderate anemia was seen in $44 \%$ and severe anemia was seen in $8 \%{ }^{13}$. Other studies have reported variable figures. Ninety percent $(90 \%)$ of the women had mild anemia while severe anemia was seen in most of the cases in other studies ${ }^{14}$. The prevalence of anemia has been reported relatively high between $33-75 \%$ in another study ${ }^{15}$.

High incidence of iron deficiency anemia has been repeatedly reported by various Pakistan studies ${ }^{16}$. Studies from other developing countries specially India and Africa report a similarly high incidence of iron deficiency anemia among pregnant women ${ }^{17}$. There is a substantial evidence that maternal iron deficiency anemia early in pregnancy can result in low birth weight subsequently to preterm delivery. In our study, preterm delivery was seen in 3\% of cases. That maternal anemia especially before mid pregnancy increases the risk of preterm delivery ${ }^{18}$.

We did not go for the iron level estimation in our patients due to its cost but because many studies have indicated that that $80 \%$ of anemia during pregnancy is because of iron deficiency of new it is most likely that iron deficiency was prevalent in this group of patients ${ }^{19,20}$.

The frequency of anemia in pregnancy speaks of the substandard health of our female population of child bearing age and shows the indifference on part of women themselves and their treating physicians towards an easily treatable pathology. By far majority of women suffer from iron deficiency anemia and superadded malnutrition.

\section{CONCLUSIONS}

Prevalence of anemia during 3rd trimester of pregnancy in our society. It can have significant effects on maternal and fetal out come. It is a preventable cause which can be treated easily. Poverty is the most important cause of anemia during pregnancy.

Copyright 27 Sep, 2014.

\section{REFERENCES}

1. Strong J, Rutherford JM, Anemia and White blood Cell disorders. In; James D, Steer PJ, Crowther CA, Weiner CP, Robson SC, Gohak B. High Risk Pregnancy management options. 4th Edition; Elsevier: St. Louis USA 2006:683-703.

2. Jetsky EA. The hematological system In: Broughtom PF, Chamberlain GVP (Eds). Clinical Physiology in Obstetrics 3rd ed. Oxford Black well Science 1998: 71110.

3. Breymann C. Current aspects of diagnosis and therapy of iron deficiency in Pregnancy: Scheweiz Rundsch Med Prax 2001, 90:1283-91.

4. Beard JL. Effectiveness and strategies of iron supplementation during Pregnancy. Am j Clin Nutr 2000; 71:1288S-94S.

5. Sally Collins, Sabaratnam Arulkumaram, Kevin Hayes, Simon Jackson, Lawrence Impey. Anemia In; Oxford handbook of obstetrics and Gynaecology $2^{\text {nd }}$ Edition; Oxford University Press: USA 2008: 192-193.

6. Mackie MJ, Ludlam CA, Haynes AP. Disease of the blood. In: Haslett C, Chilvers ER, Hunter JAA, Boon NA. Davidson's Principles and practice of medicine. 18th ed. Edinburgh. Churchill Livingstone 1999:737-99.

7. Marti A, Pena MG, Muno ZS, Lanas F, Comunian G. Association between Prematurity and maternal anemia in vene zuelan Pregnant women during third trimester at labour. Arch Latinoam Nutr 2001; 51: 44-8.

8. Badshah S, Mason L, MC Kelvie K, Payne, R Lisboa $\mathrm{PJa}$. Risk factors for low birth weight in the publichospitals at Peshawar, NWFP-Pakistan. BMC Public Health 2008; 8:197.

9. Ticconi C, Mapfamo M, Dorrucci M, Naha N, Tarira E, Pietropolli A, et al. Effect of maternal HIV and malaria infection on Pregnancy and Perinatal outcome in Zimbabwe. J Acquire Immune Defic Syndr 2005, 34:289-94.

10. Dimcc, Onah HE. The prevalence of anemia in Pregnant Women at booking in Enugo, South Eastern Nigeria. Med Gen MED. 2007; 9(3):11. 
11. BorJa JB, Adair LS: Assessing the net effect of young maternal age on birth weight. Am J Hum Biol 2003; 15: 733-40.

12. Valero De Bernabe J, Soriano T, Albala deJo R, Juarran ZM, Calle ME, Martine ZD, et al. Risk factors for low birth weight : a review. Eur J Obstet Gyne col Reprod Biol 2004; 116(1): 3-15.

13. Awan MM Akber MA, Khan MI. A study of anemia in pregnant women of Railway colony, Multan. Pak J Med. Res 2004; 43:11-4.

14. Siega-RizAM, Adair LS, HoblCJ. Maternal Hematologic changes during pregnancy and effect of iron status on preterm delivery in a west Los Angles Population. Am J Perinatal 1998; 15:515-522.

15. Kimanuka GN, Ishara Za Wk, Mahmoud S. Iron Status of Pregnant women at first anthenatal booking in Mbara University Teaching Hospital, Trop Doct 2000; 29:228-230.

16. Wali A, Mushtaq A, Nilofer, Comparative study efficacy, safety and compliance of intravenous iron sucrose and Intra muscular Iron sorbitol in iron deficiency anemia of Pregnancy. J Pak. Med Assoc 2002; 52:3925.

17. Gautam VP, Bansaly, Tanega DK, Saha R. Prevalence of anemia amongst Pregnant Women and its socio demographic associates in a rural area of Delhi. Indian J. Community Med 2002; 27:157-60.

18. Scholl TQ, Reilly T. Anemia, Iron and pregnancy outcome. J Nutr 2002; 443S-447S.

19. Khan MM. Effect of maternal anemia on fetal parameters. J Ayub Med Col Abottabad 2001; 13 (2): $38-41$.

20. YIPR. Significance of an abnormally low or high hemoglobin concentration during pregnancy. Special Consideration of iron nutrition. Am J Clin Nutr 2000; 72 (Suppl.) 272S-279S.

\section{Never make permanent decisions on temporary feelings.}

